\title{
Pengaruh Lingkungan Kerja Dan Reward Terhadap Motivasi Kerja Dan Kepuasan Kerja Karyawan \\ (Studi Kasus Pada Karyawan PT. Kaliaren Jaya Plywood)
}

\author{
Eva Nurhalipah', Arif Haryana², Nurminingsih ${ }^{3}$ \\ Program Studi Administrasi Bisnis Program Magister Universitas Respati Indonesia \\ email:eva.nurhalipah95@gmail.com,arifharyana@gmail.com,nings@urindo.ac.id
}

\begin{abstract}
ABSTRAK
Masalah dalam penelitian ini yaitu Motivasi Kerja dan Kepuasan Kerja PT. Kaliaren jaya Plywood masih rendah, hal ini ditujukkan dengan adanya keluar masuk karyawan setiap bulannya, dimana hal tersebut dapat disebabkan oleh berbagai fakktor diantaranya lingkungan kerja dan reward. Hipotesis yang diajukan yaitu slingkungan kerja berpengaruh signifikan terhadap motivasi kerja, reward berpengaruh siginifikan terhadap motivasi kerja, lingkungan kerja berpengaruh signifikan terhadap kepuasan kerja, reward berpengaruh siginifikan terhadap kepuasan kerja dan motivasi kerja berpengaruh signifikan terhadap kepuasan kerja. Metode yang digunakan adalah metode kuantitatif. Dalam penelitian ini responden berjumlah 100 orang. Teknik pengumpulan data menggunakan angket. Metode yang dapat digunakan dalam penelitian ini adalah dengan menggunakan analisis Structural Equation Modeling (SEM) yang berbasis varians yaitu Partial Least Square (PLS). Dari hasil uji hipotesis menunjukan bahwa lingkungan kerja berpengaruh signifikan terhadap motivasi kerja,, reward berpengaruh signifikan terhadap motivasi kerja, lingkungan kerja tidak berpengaruh signifikan terhadap kepuasan kerja, reward tidak berpengaruh signifikan terhadap kepuasan kerja, dan motivasi kerja berpengaruh signifikan terhadap kepuasan kerja
\end{abstract}

Kata Kunci : Lingkungan Kerja, Reward, Motivasi Kerja, dan Kepuasan Kerja 


\begin{abstract}
The problem of the research was work motivation and job satisfaction PT. Kaliaren Jaya Plywood has low, it was showed with the employee outflow every month, it could be caused by various factors such as work environment and reward. The hypothesis of the research was the work environment had a significant effect on work motivation, reward had a significant effect on work motivation, work environment had a significant effect on job satisfaction, reward had a significant effect on on job satisfaction, work motivation had a significant effect on job satisfaction. The method of the reserach used quantitative method. In reserach, the response and amounted to 100 people. Data collection techniques in this reserach used questionnaires. Method that can be used in this research is to use analysis of Structural Equation Modeling (SEM) based variance Partial Least Square (PLS). From result of hypothesis test indicated that work environment had significant effect on work motivation, reward had significant effect on work motivation, work environment had no significant effect on job satisfaction, reward had no significant effect on job satisfaction, and work motivation had significant effect on job satisfaction.
\end{abstract}

Keywords: Work Environment, Reward, Work Motivation, and Job Satisfaction 


\section{PENDAHULUAN}

Setiap lingkungan bisnis
dituntut untuk
mengoptimalkan sumber daya
manusia dan bagaimana sumber
daya manusia dikelola.

Pengelolaan sumber daya manusia tidak lepas dari faktor karyawan yang diharapkan dapat berprestasi sebaik mungkin demi mencapai tujuan organisasi.

Motivasi merupakan daya dorong yang mengakibatkan seseorang anggota organisasi mau dan rela untuk mengerahkan kemampuan dalam bentuk keahlian atau keterampilan tenaga dan waktunya untuk menyelenggarakan berbagai kegiatan yang menjadi tanggung jawabnya dan menunaikan kewajibannya, dalam rangka pencapaian tujuan dan berbagai sasaran organisasi yang telah ditentukan sebelumnya (Siagian 2012:6). Kepuasan kerja adalah sikap emosional yang sangat menyenangkan dan sangat mencintai pekerjaannya. Kepuasan kerja (job satisfaction) karyawan harus diciptakan sebaik-baiknya agar moral kerja, dedikasi, kecintaan, dan kedisiplinan karyawan meningkat. Sikap ini dicerminkan oleh moral kerja, kedisiplinan, dan prestasi kerja (Hasibuan 2007:202).

Faktor yang mempengaruhi motivasi kerja dan kepuasan kerja salah satu nya adalah lingkungan kerja. Lingkungan kerja adalah sesuatu keadaan yang ada di sekitar seorang pekerja untuk melakukan pekerjaan nya dan menjalankan suatu tugas nya, lingkungan kerja ini mempunyai pengaruh atas kemajuan nya suatu organisasi dan instansi. Selain faktor lingkungan kerja, faktor lain yang berpengaruh terhadap motivasi kerja dan kepuasan kerja adalah salah satunya Reward. Reward adalah suatu imbalan atau suatu penghasilan karyawan yang diberikan dari pihak prusahaan kepada karyawan baik secara bentuk maretial atau non material. Reward diberikan dengan tujuan untuk mengapresiasi kepada karyawan yang berprestasi supaya karyawan tersebut loyal kepada perusahaan tempat bekerjanya.

PT. Kaliaren yang beralamat di Jalan Raya Caracas Mandirancan KM 1. RT 28 RW 10 Desa Sampora Kecamatan Cilimus Kabupaten Kuningan, Jawa Barat merupakan salah satu perusahaan yang memproduksi kayu lapis. Motivasi kerja dan Kepuasan Kerja yang tinggi dari karyawan sangat diperlukan untuk mencapai tujuan perusahaan. Sebagai perusahaan yang mengharapkan tujuan tersebut, perusahaan harus memperhatikan sumber daya manusia nya agar dapat meningkatkan motivasi kerja dan kepuasan kerja karyawan yang maksimal dalam melakukan pekerjaanya sehingga tujuan yang diharapkan perusahaan tersebut dapat tercapai dengan baik. 
baiknya supaya moral kerja, dedikasi, kecintaan, dan kedisiplinan karyawan meningkat. Sikap ini dicerminkan oleh moral kerja, kedisiplinan, dan prestasi kerja.

\section{Lingkungan Kerja}

Lingkungan kerja adalah keseluruhan alat perkakas dan bahan yang dihadapi sekitarnya di mana seseorang berkerja, metode kerjanya, serta pengaturan kerjanya baik sebagai perseorangan maupun sebagai kelompok.

\section{Reward}

Reward adalah hasil - hasil atas apa yang sudah diperoleh dari pekerjaan yang diberikan bisa berupa upah atau gaji bahkan insentif yang dapat memberikan prestasi kerja melebihi standard dan melebi target kinerja yang diharapkan.

\section{METODE PENELITIAN}

Penelitian ini termasuk jenis penelitian kuantitatif. Penelitian ini dilakukan di PT Kaliaren Jaya Plywood yang beralamat yang beralamat di Jalan Raya Caracas Mandirancan KM 1.
RT 28 RW 10 Desa

Sampora Kecamatan Cilimus Kabupaten Kuningan, Jawa Barat. Populasi dalam dalam penelitian ini adalah seluruh karyawan PT Kaliaren Jaya Plywood. Sampel dalam penelitian ini adalah populasi penelitian yakni seluruh karyawan yang berjumlah 100 yang ditetapkan menjadi sampel sehingga teknik pengambilan sampel yang tepat adalah total sampling. Pengumpulan diperoleh melalui data primer dan data sekunder. Analisis data dan pengujian hipotesis menggunakan Structural Equation Model (SEM) dengan menggunakan software partial least square (PLS). Adapun tahap-tahap pengujiannya outer dan inner model meliputi uji Convergent Validity, Discriminant Valdity, Composite Reliability, R-square dan path koefisien. 


\section{HASIL PENELITIAN DAN PEMBAHASAN}

Berdasarkan penelitian yang telah dilakukan outer model penelitian adalah sebagai berikut :

\section{Gambar 1. Outer Model}

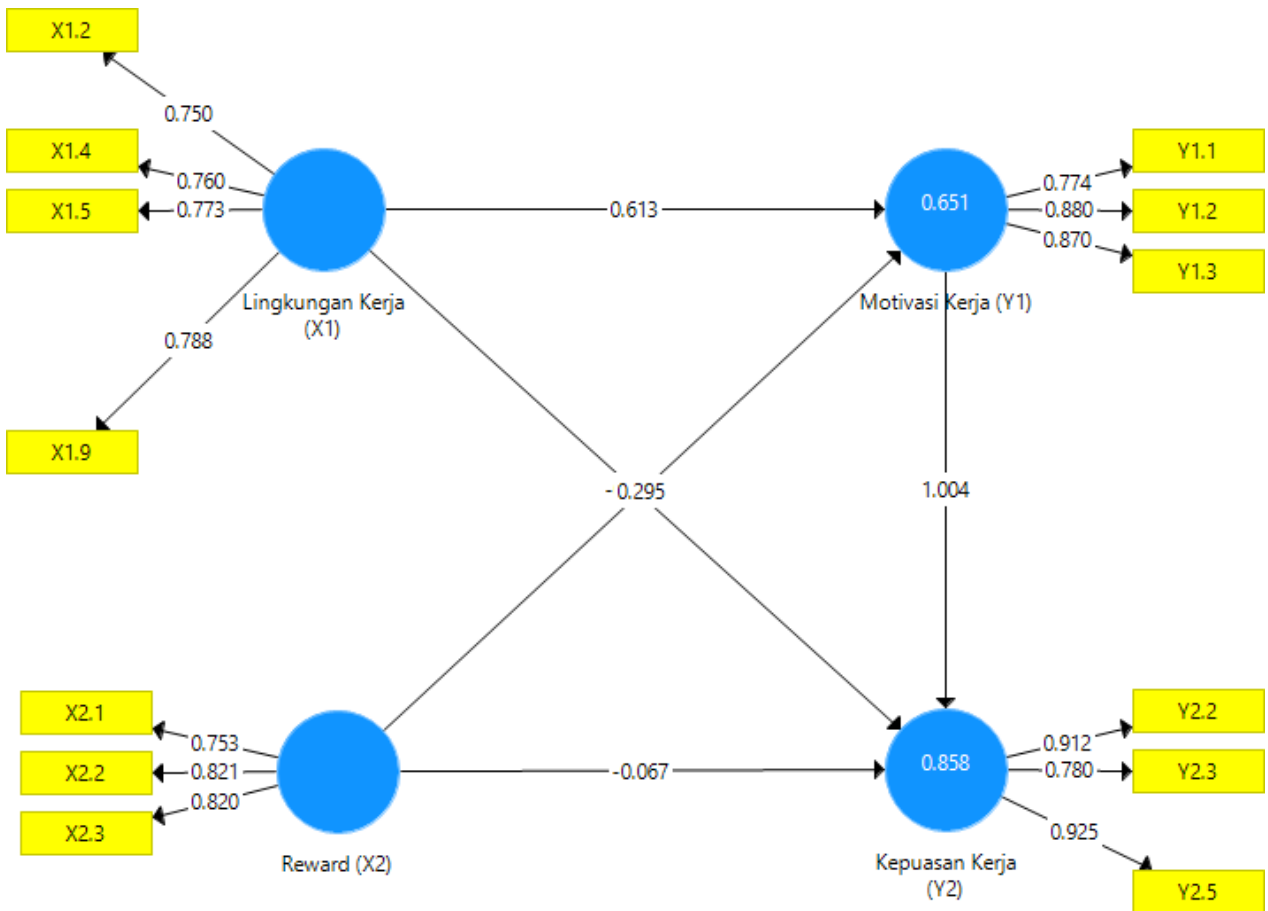

Sumber : SmartPLS, 2020

\begin{abstract}
Berdasarkan hasil uji validitas variabel lingkungan kerja, reward, motivasi kerja dan kepuasan kerja didapatkan hasil bahwa semua item pernyataan dinyatakan valid karena nilai outer loading $>0.70$. Hal tersebut berarti butir-butir pernyataan dalam variabel lingkungan kerja,
\end{abstract}

reward, motivasi kerja dan kepuasan kerja dinyatakan valid dan layak digunakan sebagai instrumen penelitian.

Uji reliabilitas menunjukkan sejauh mana suatu alat ukur yang dapat memberikan hasil yang relative sama apabila dilakukan pengukuran kembali pada subyek yang sama. Uji reliabilitas dapat dilihat pada Tabel 1 sebagai berikut: 


\section{Tabel 1}

Uji Reliabilitas

\begin{tabular}{|l|l|l|l|l|}
\hline & $\begin{array}{l}\text { Cronbach's } \\
\text { Alpha }\end{array}$ & rho_A & $\begin{array}{l}\text { Composite } \\
\text { Reliability }\end{array}$ & $\begin{array}{l}\text { Average } \\
\text { Variance } \\
\text { Extracted } \\
\text { (AVE) }\end{array}$ \\
\hline Lingkungan Kerja (X1) & 0.830 & 0.750 & 0.907 & 0.590 \\
\hline Reward (X2) & 0.719 & 0.308 & 0.841 & 0.638 \\
\hline Motivasi Kerja (Y1) & 0.796 & 0.343 & 0.880 & 0.710 \\
\hline Kepuasan Kerja (Y2) & 0.844 & 0.237 & 0.852 & 0.766 \\
\hline
\end{tabular}

Sumber : Data diolah SEM - SmartPLS

Hasil pengolahan uji reliabilitas pada variabel lingkungan kerja, reward, motivasi kerja dan kepuasan kerja didapatkan nilai Composite Reliability (CR) untuk semua konstruk lebih besar dari 0,7 yang menunjukkan bahwa semua konstruk pada model diestimasi memenuhi kriteria discriminant validity. Selanjutnya Menurut Hair et., al (1998), direkomendaskan nilai Average Variance Extracted ( $A V E$ ) untuk semua konstruk harus lebih besar dari 0,5. Berdasarkan tabel 1 menunjukkan bahwa nilai akar dari $A V E$ untuk setiap konstruk adalah lebih besar dari 0,5 atau lebih.

\begin{abstract}
Dengan demikian hasil pengujian Average Variance Extracted ( $A V E$ ) semua reliable. Berdasarkan hasil seluruh uji instrument dari uji validitas dan reliabilitas dinyatakan bahwa semua butir pernyataan memenuhi persyaratan untuk dipakai dalam instrument penelitian.
\end{abstract}

Selanjutnya Pengujian Model Struktural (Inner Model)

Analisis Variant (R2) atau

Uji Determinasi yaitu untuk mengetahui besar pengaruh variabel independen terhadap Dependen tersebut, nilai dari koefisien determinasi dapat ditunjukkan pada tabel 2 


\section{Tabel 2}

\section{R-SQUARE}

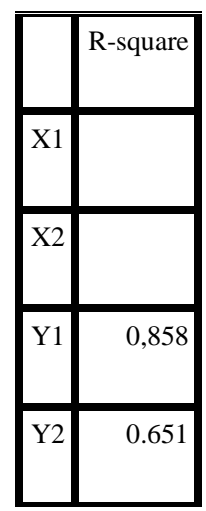

Sumber: Ouput SmartPLS 3, data primer diolah 2020

Tabel di atas memberikan nilai 0,858 untuk konstruk Motivasi kerja yang berarti bahwa lingkungan kerja dan reward mampu menjelaskan varians motivasi kerja sebesar 85,8\%. Nilai $R$ juga terdapat pada Kepuasan kerja yang dipengaruhi oleh lingkungan kerja, reward dan motivasi kerja yaitu sebesar 0,651

Tabel 3 Hasil

Uji Hipotesis

\begin{tabular}{|l|l|l|l|l|l|}
\hline & $\begin{array}{l}\text { Original } \\
\text { Sample } \\
\text { Estimasi(O) }\end{array}$ & Sample Mean (M) & $\begin{array}{l}\text { Standard Deviation } \\
\text { (STDEV) }\end{array}$ & $\begin{array}{l}\text { T Statistics } \\
\text { (|O/STDEV|) }\end{array}$ & P Values \\
\hline $\begin{array}{l}\text { HI : Lingkungan Kerja } \\
\text { (X1) -> Motivasi Kerja } \\
\text { (Y1) }\end{array}$ & 0.613 & 0.617 & 0.082 & 7.464 & $\mathbf{0 . 0 0 0}$ \\
\hline $\begin{array}{l}\text { H2 : Reward (X2) -> } \\
\text { Motivasi Kerja (Y1) }\end{array}$ & 0.295 & 0.300 & 0.092 & 3.194 & $\mathbf{0 . 0 0 1}$ \\
\hline $\begin{array}{l}\text { H3 : Lingkungan Kerja } \\
\text { (X1) -> Kepuasan } \\
\text { Kerja (Y2) }\end{array}$ & -0.050 & -0.061 & 0.075 & 0.677 & $\mathbf{0 . 4 9 9}$ \\
\hline $\begin{array}{l}\text { H4 : Reward (X2) -> } \\
\text { Kepuasan Kerja (Y2) }\end{array}$ & -0.067 & -0.066 & 0.045 & 1.497 & $\mathbf{0 . 1 3 5}$ \\
\hline $\begin{array}{l}\text { H5 :Motivasi Kerja } \\
\text { (Y1) -> Kepuasan } \\
\text { Kerja (Y2) }\end{array}$ & 1.004 & 1.015 & 0.056 & & $\mathbf{0 . 0 0 0}$ \\
\hline
\end{tabular}

Sumber : Data diolah SEM-Smart-PLS 
A. H1 : Tabel diatas menunjukkan bahwa hubungan antara lingkungan kerja (X1) dengan motivasi kerja (Y1) adalah signifikan dengan T-Statistic sebesar 7,464 (> 1,96). Nilai original sample estimate adalah positif yaitu sebesar $\quad 0,613 \quad$ yang menunjukkan hubungan antara lingkungan kerja (X1) dengan motivasi kerja (Y1) adalah positif. Dengan demikian hipotesis H1 dalam penelitian ini yang menyatakan bahwa lingkungan kerja (X1) berpengaruh dengan motivasi kerja (Y2) Diterima.

B. H2 : Tabel diatas menunjukkan bahwa hubungan antara Reward (X2) dengan motivasi kerja (Y1) adalah signifikan dengan $\mathrm{T}$ Statistic sebesar 3,194 (> 1,96). Nilai original sample estimate adalah positif yaitu sebesar 0,295 yang menunjukkan hubungan antara Reward (X2) dengan motivasi kerja (Y1) adalah positif. Dengan demikian hipotesis H2 dalam penelitian ini yang menyatakan bahwa Reward (X2) berpengaruh dengan motivasi kerja (Y2) Diterima.

C. H3 : Tabel diatas menunjukkan bahwa hubungan antara lingkungan kerja (X1) dengan kepuasan kerja (Y2) adalah tidak signifikan dengan $\mathrm{T}$ Statistic sebesar 0,677 (< 1,96). Nilai original sample estimate adalah negatif yaitu sebesar 0,050 yang menunjukkan hubungan antara lingkungan kerja (X1) dengan kepuasan kerja (Y2) adalah negatif. Dengan demikian hipotesis H3 dalam 
penelitian ini yang

menyatakan bahwa

lingkungan kerja (X1)

berpengaruh dengan

kepuasan kerja (Y2)

Ditolak.

Nilai original sample

estimate adalah negatif

yaitu sebesar -0,067 yang

menunjukkan hubungan

D. H4 : Tabel diatas

antara Reward (X2)

menunjukkan bahwa

hubungan antara Reward

(X2) dengan kepuasan

kerja (Y2) adalah tidak

signifikan dengan $\mathrm{T}$ -

Statistic sebesar 1,497 (<

dengan kepuasan kerja

(Y2)adalah negatif.

Dengan demikian

hipotesis H4 dalam

penelitian ini yang

1,96).

menyatakan bahwa

Reward (X2) berpengaruh

dengan kepuasan kerja

(Y2) Ditolak. 
E. H5 : Tabel diatas menunjukkan bahwa hubungan antara motivasi kerja (Y1) dengan kepuasan kerja (Y2) adalah signifikan dengan T-Statistic sebesar 17,811 (> 1,96). Nilai original sample estimate adalah positif yaitu sebesar 0,295 yang menunjukkan hubungan antara motivasi kerja (Y1) dengan kepuasan kerja (Y2) adalah positif. Dengan demikian hipotesis H5 dalam penelitian ini yang menyatakan bahwa motivasi berpengaruh dengan kepuasan kerja (Y2) Diterima.

\section{PEMBAHASAN}

Pengaruh Lingkungan Kerja Terhadap Motivasi Kerja

Hasil penelitian ini menunjukkan bahwa Lingkungan Kerja berpengaruh secara signifikan terhadap Motivasi Keja. Hal ini ditunjukkan dengan nilai $\mathrm{T}$ - Statistic sebesar 7,464 $(>1,96)$. Nilai original sample estimate adalah positif yaitu sebesar 0,613 yang menunjukkan hubungan antara lingkungan kerja (X1) dengan motivasi kerja (Y1) adalah positif.

\section{Pengaruh Reward Terhadap Motivasi} Kerja

Hasil penelitian ini menunjukkan bahwa Reward berpengaruh secara signifikan terhadap Motivasi Keja. Hal ini ditunjukkan dengan nilai $\mathrm{T}$ Statistic sebesar 3,194 (>1,96). Nilai original sample estimate adalah positif yaitu sebesar 0,295 yang menunjukkan hubungan antara lingkungan kerja (X2) dengan motivasi kerja (Y1) adalah positif.

Pengaruh Lingkungan Kerja Terhadap Kepuasan Kerja Hasil penelitian ini menunjukkan bahwa Lingkungan Kerja tidak berpengaruh secara signifikan terhadap Kepuasan Keja. Hal ini ditunjukkan dengan nilai $\mathrm{T}$ - Statistic sebesar 3,677 $(<1,96)$. Nilai original sample estimate adalah negatif yaitu sebesar 0,050 yang menunjukkan hubungan antara lingkungan kerja (X1) dengan motivasi kerja (Y2) adalah negatif. 
Pengaruh Motivasi Terhadap Kepuasan Kerja

Hasil penelitian ini menunjukkan bahwa Motivasi Kerja berpengaruh secara signifikan terhadap Kepuasan Keja. Hal ini ditunjukkan dengan nilai $\mathrm{T}$ - Statistic sebesar 17,811 $(>1,96)$. Nilai original sample estimate adalah positif yaitu sebesar 0,295 yang menunjukkan hubungan antara lingkungan kerja (Y1) dengan motivasi kerja (Y2) adalah positif. Hasil ini sejalan dengan penelitian Rizwan Saleem, Azeem Mahmood, Asif Mahmood (2010), Hasnur Wasyahdio (2015) yang menyatakan bahwa Motivasi Kerja berpengaruh positif dan signifikan terhadap Kepuasan Kerja.

\section{KESIMPULAN DAN SARAN}

\section{Kesimpulan}

1. Hasil penelitian menunjukkan bahwa Lingkungan Kerja berpengaruh positif dan signifikan terhadap Motivasi Keja.

2. Hasil penelitian menunjukan bahwa Reward berpengaruh positif dan signifikan terhadap Motivasi Keja.

3. Hasil penelitian menunjukkan bahwa Lingkungan Kerja berpengaruh negatif dan tidak signifikan terhadap Kepuasan Keja.

4. Hasil penelitian menunjukkan bahwa Reward berpengaruh negatif dan tidak signifikan terhadap Kepuasan Keja.

5. Hasil penelitian menunjukkan bahwa Motivasi Kerja berpengaruh positif dan signifikan terhadap Kepuasan Keja

\section{Saran}

1. Bagi Perusahaan

a Perusahaan perlu meningkatkan kondisi lingkungan kerja yang lebih kondusif, sehingga mampu memberikan suasana kerja yang nyaman dan berdampak baik pada motivasi kerja dan pada kepuasan kerja.

b. Perusahaan sebaiknya lebih memperhatikan karyawan yang berprestasi baik dengan memberikan reward dan memberikan balas jasa yang adil dan layak. Hal ini dapat memotivasi karyawan dan meningkatkan kepuasan kerja 
c. Perusahaan seharusnya mengerti dan mengetahui apa yang dibutuhkan para karyawan dan mengetahui keinginankeinginan apa yang membuat karyawan merasa lebih puas, sehingga dapat meningkatkan kepuasan kerja yang sesuai dengan yang karyawan rasakan.

2. Bagi Penelitian Mendatang a. Penelitian dimasa yang akan datang sebaiknya memperluas variabel penelitian sehingga motivasi kerja dan kepuasan kerja karyawan PT. Kaliaren Jaya Plywood bisa lebih meningkat. b. Diharapkan penelitian selanjutnya dapat mengkaji lebih dalam tentang lingkungan kerja, reward, terhadap motivasi kerja dan terhadap kepuasan kerja PT. Kaliaren Jaya Plywood agar diperoleh gambaran yang lebih lengkap lagi, sehingga diharapkan hasil penelitian yang akan datang lebih baik dari penelitian ini.

c. Penelitian yang dilakukan hanya menggunakan metode analisis data dengan PLS. Oleh karena itu penelitian selanjutnya menggunakan metode analisis lainnya seperti LISREL, AMOS, dan sebagainya. 


\section{DAFTAR PUSTAKA}

Agus Ahyari, 1994. Manajemen

Produksi, Pengendalian

Produksi, Edisi 4, Yogyakarta. BPFE UGM.

Anwar Prabu Mangkunegara, 2010. Manajemen Sumber Daya Manusia Perusahaan, Remaja Rosdakarya. Bandung.

Bangun, Wilson. 2012.

Manajemen Sumber Daya

Manusia, Erlangga, Bandung.

Burhan Nurgiyantoro dkk. 2004.

Statistik Terapan untuk

Penelitian Ilmu-Ilmu Sosial. Yogyakarta. Gadjah Mada University Press.

Danang, Sunyoto. 2012.

Manajemen Sumber Daya

Manusia. Jakarta : PT Buku

Seru. Dimyati dan Mudjiono.

2002. Motivasi Kepemimpinan.

Jakarta

Edy Sutrisno, 2014. Manajemen Sumber Daya Manusia. Cetak ke Enam. Pranada Media Group, Jakarta.

Ferdinand, Augusty. 2014. Metode Penelitian Manajemen, Semarang,
Badan Penerbit

Universitas Diponegoro.

Ghozali. 2013. Aplikasi Analisis

Multivariate dengan

Pogram SPSS. Statistic

Badan Penerbit

Universitas Diponegoro

Ghouzali, Saydam.1996. Manajemen

Sumber Daya Manusia. Jakarta

Ghozali, Imam. 2013. Aplikasi Analisis Multivariatdengan Program IBM SPSS 21.

Edisi 7. Penerbit Universitas Diponegoro, Semarang.

Hadari Nawawi. 2005.

Manajemen Sumber Daya

Manusia Untuk Bisnis

Yang Kompetitif, Cetakan

ke-4, Gajah Mada

Univercity Press, Yogyakarta.

Haedar $^{1}$, Saharudin ${ }^{2}$, Herlangga. $\mathrm{H}^{3}$, 2015. Pengaruh Lingkungan Kerja dan Masa Kerja terhadap Kepuasan Karyawan pada PT. Hadji Kalla Palopo.

Handoko, T. Hani 2011. Manajemen Personalia dan Sumber Daya Manusia. Yogyakarta : Penerbit BPFE.

Hamdi, Asep Saepul. E.

Bahruddin. 2014. Metode Penelitian Kuantitatif Aplikasi dalam Pendidikan, Yogyakarta : Deepublisher.

Hasnur Wansyahdio, 2015. Pengaruh Motivasi Kerja Lingkungan Kerja 
terhadap Kepuasan Kerja

Karyawan pada Pabrik

PT. Eka Dura Indonesia 
Jakarta : Ghalia

Husaini Usman dan Purnomo Setiady Akbar. 2006. Pengantar Statistika, Jakarta.

Bumi Aksara.

Keputusan Menteri Kesehatan RI no.

261/Menkes/SK/II/1998 tentang

Persayaratan Kesehatan

Lingkungan Kerja.

Luthans, 2001, Perilaku Organisasi.

Edisi Sepuluh. PT. Andi : Yogyakarta.

. 2006. Perilaku Organisasi.

Edisi Sepuluh. PT. Andi : Yogyakarta.

Malayu, Hasibuan. 2001. Manajemen

Sumber Daya Manusia. Bumi Aksara. Jakarta.

2007. Manajemen

Sumber Daya Manusia. Bumi Aksara, Jakarta.

2013. Manajemen

Sumber Daya Manusia. Bumi Aksara,. Jakarta.

2014.

Manajemen

Sumber Daya

Manusia

(Edisi Revisi).

Bumi Aksara.

Jakarta.

Mukrodi dan Komarudin, 2017.

Pengaruh Kepemimipinan Dan

Motivasi Terhadap Kepuasan

Kerja Karyawan Di PT. Asuransi

Jiwa Mega Life.

Mutiara S. Panggabean. 2002.

Manajemen Sunber Daya

Manusia. Bogor: Ghalia

Indonesia.
Indonesia. Priyatno. 2008.

Mandiri Belajar SPSS.

Yogyakarta : Mediakom 2009. 5 Jam Belajar Olah Data dengan SPSS 17. Yogyakarta : Andi

Rasfiani Damsjik, 2017. Pengaruh Lingkungan Kerja Fisik, Motivasi dan Komunikasi Terhadap Kepuasan Kerja Pegawai Pada Kantor Badan Perencanaan

Pembangunan Daerah (BAPPEDA). Kabupaten Donggala.

Richard L. Hughes, Robert C. Ginnett, and Gordon J. Curphy. 2012. Leadership, Enhancing the Lessons of Experience, Alih Bahasa : Putri Izzati, Jakarta : Salemba Humanika.

Rivai, Viethzal, 2004. Manajemen Sumber Daya Manusia Untuk Perusahaan, Murai Kencana Jakarta.

Robbins, Stephen P. dan Coulter, Mary, 2010. Manajemen (edisi kesepuluh) Jakarta : Erlangga

Rochaety, dkk. 2007, Metodologi Penelitian Bisnis dcengan Aplikasi SPSS. Jakarta : Mitra Wacana Media.

Nitisemito, Alex S.. 2002.

Manajemen Personalia. 
Supardi. 2005. Metode

Sandi $\mathrm{J}^{1}$, Djumadi ${ }^{2}$, Anwar Alaydrus $^{3} \quad, \quad 2016$. Pengaruh Lingkungan Kerja Fisik Dan Motivasi Terhadap Kepuasan Kerja Pegawai SMA Negeri 2 Sendawar.

Sedarmayanti. 2007. Sumber Daya Manusia dan Produktivitas Kerja. Bandung : CV Mandar Maju.

Siagian, Sondang P, 2013. Manajemen Personalia dan Sumber Daya Manusia. Edisi Satu, Cetakan Ke Depuluh Satu. Penerbit Bumi Aksara, Jakarta

Sihombing, Umberto. 2004. Pengaruh Keterlibatan Dalam Pengambilan Keputusan, Penilaian pada Lingkungan Kerja dan Motivasi Berprestasi Terhadap Kepuasan Kerja Pamong Praja. http://www.dupdiknas.go. ig..

Suharsaputra, Uhar. 2012. Metode Penelitian : Kuantitatif, Kualitatif, dan Tindakan. Bandung : Refika Aditama.

Suharsimi, Arikunto. 2010.

Prosedur Penelitian. Jakarta :

Rineka Cipta. Sukmadinata, 2006. Metode Penelitian

Pendidikan. Remaja

Rosdakarya, Bandung.
Penelitian Ekonomi dan

Bisnis. Yogyakarta: UII Press.

Sutrisno, Edy, 2014. Manajemen Sumber Daya Manusia Edisi 1 Cetakan Kedua, Kencana, Jakarta.

Sihombing, 2001.

Manajemen

Produksi, BPFE.

Yogyakarta.

Sugiyono. 2007

Metodologi

Penelitian Bisnis.

Jakarta : PT.

Gramedia

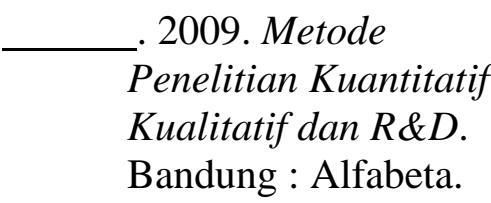

Bandung : Alfabeta 2013. Statistic untuk penelitian.

Bandung : Alfabeta

Wibowo. 2007.

Manajemen Kinerja.

Jakarta : PT Raja

Grafindo Parsada

Wursanto, Ignatius.

2003. 


\section{Dasar-Dasar Ilmu}

\section{Organisasi. Yogyakarta}

: Andi. 